\title{
A Course Approach to Student Transition to University: A Case Study in Agricultural Business Management
}

\author{
Yann Guisard ${ }^{1}$, Karl Behrendt ${ }^{1}$, Peter Mills ${ }^{1}$, Shevahn Telfser ${ }^{1}$, Warwick Weatley ${ }^{1}$, \\ Carole Hunter ${ }^{2}$, Rebecca Acheson ${ }^{3}$, Zelma Bone ${ }^{4}$ \\ ${ }^{1}$ School of Agricultural and Wine Sciences, Charles Sturt University, Orange, Australia \\ ${ }^{2}$ Flexible Learning Institute, Charles Sturt University, Orange, Australia \\ ${ }^{3}$ Division of Learning and Teaching services, Charles Sturt University, Orange, Australia \\ ${ }^{4}$ School of Business, Charles Sturt University, Orange, Australia \\ Email: yguisard@csu.edu.au
}

Received September $8^{\text {th }}, 2012$; revised October $7^{\text {th }}, 2012$; accepted October $20^{\text {th }}, 2012$

\begin{abstract}
The focus of this paper is to present a case study of an integrated course approach to student transition in an undergraduate agricultural business management program. This wholistic approach is particularly relevant to courses with small student intake (defined here as less or equal to 20 full time students). These small intakes represent approximately 38\% of all intakes in Australian universities. Most universities have an orientation week with generic and course specific activities to assist students in their transition to university life but very few have a "total package" of sustained transitional support with an overnight tour, mentoring program, curriculum mapping and course design for all of the first stage subjects as just some of their strategies. The transition was planned to take place over the entire first stage of the course. A course team working collaboratively and cohesively was paramount to the success of this project. The approach was first implemented in 2010 and three years of data are presented here. These data clearly demonstrate that although student grades did not significantly improve, student satisfaction and perception of the "worth" of the various fundamental subjects taught in the first year of their course increased. This is associated with a recent decrease in first year student attrition. Finally and perhaps more importantly, academics reported that students seemed to display a higher standard of academic literacy and deeper critical thinking in their various assessment tasks.
\end{abstract}

Keywords: Undergraduate; First Year Experience; Integrated Curriculum; Mentoring; Academic Literacies; Course Mapping; Orientation Tour

\section{Introduction}

In 2009, Charles Sturt University's (CSU) Bachelor of Agricultural Business Management (BABM) course team reviewed the design and implementation of the first year of the course (at CSU, a "course" is a complete program over 3 or 4 years, composed of "subjects"). Although all courses at CSU are subjected to a normal cycle of course review, a range of internal and external pressures warranted the immediate onset of this project. CSU had recently implemented its CSU Degree framework, a course-based approach to curriculum renewal that incorporates a range of commitments to students (CSU, n.d.), including a supported transition into the first year of study and a range of generic skills and experiences. These moves aligned with industry demands for graduates with higher communication and digital literacy skills.

Teaching staff were similarly placing their own pressures on the course. Working cross campus, cross discipline and crossFaculty meant that subject coordinators often worked in isolation; many felt frustrated by inconsistencies in the first year subjects and the perceived overall lack of progression in academic skills during that first year.

Further pressures on the course arose from increasing student diversity and need. Students come to the BABM course through multiple entry pathways and a wide range of admission scores. There is also much variance in levels of previous agricultural experience, with students drawn equally from urban and regional backgrounds. Similar diversity is seen in typical demographics, including age ranges and the need to work while studying. The course's inability to accommodate these diverse needs was perceived to be a contributing factor towards high levels of attrition of first year internal students and low progression rates.

Bringing these pressures together was the team's strongly held belief that a good overall student experience had historically been the most successful marketing strategy for the course. The team therefore embarked on a course-based approach, focusing on improving the student experience in first year subjects, to yield a more integrated and effective solution.

This "solution" did not come automatically, and the course team found that they also went through a transition in thinking about the first year experience that took time and perseverance. Conversations moved from reporting grades and identifying "at risk" students to peer evaluation of subjects and shared decision-making and development. The group benefited greatly from the inclusion of Educational Designers (EDs) who provided a successful link between teaching theories and practical teaching applications.

\section{Background}

While there has been much activity in the past few years re- 
lated to the transition of students into higher education, largely due to Kift's (2009) work in this area, there is still no single, agreed-upon definition of transition in this context (Ecclestone \& Biesta, 2010). One of the most recent definitions comes from Gale and Parker (2011: p. 25): "the capacity to navigate change”. It is a useful definition, as it highlights that transition can be more than a linear progression from one state to another; it relates to how one engages with change, often without "having full control over and/or knowledge about what the change involves” (Gale \& Parker, 2011: p. 25).

The first full opportunity universities have to engage students in this process of navigating change is the first year experience (called first "stage" here, due to CSU's large number of parttime students to whom "first year" can take two years or more to complete). It is an important opportunity which, as Upcraft, Gardner and Barefoot (2005) found, is paramount in determining the students' overall success at university. Indeed, the significance of the first stage is considered so great that Kift, Nelson and Clarke (2010) advocate the need for a "transition pedagogy" as a guiding philosophy framed around intentional curriculum design that scaffolds, mediates and supports first year learning. Kift's six curriculum design principles-transition, diversity, design, engagement, assessment, and evaluation and monitoring - have been widely adopted at many institutions, including CSU, and have been an incredibly useful "foothold" for academics as they start to consider how to better support learners in developing capacities for navigating change during the myriad of transitions they will experience as professionals and individuals.

\section{Transition as Induction}

The traditional approach to addressing first stage transition has been one of induction (Gale \& Parker, 2011), whereby universities use "student orientation week" to familiarise and socialise students into the university context through a barrage of information and "mini-events". While these activities are often convenient for the institution, they have been less successful in addressing the diversity of student needs, with information overload and lack of engagement being common (Colclough, Kimmins, Harmes, \& Henderson, 2011). Furthermore, offcampus students are usually excluded.

Leske (2008) suggests a more scaffolded student induction, embedded into class time with required information strategically timed to be given to students "when they need it". Similarly, Leske recommends using technology to involve a wider range of students, and a focus not only on academic induction, but also the social aspects of university life.

Another typical "transition as induction" initiative is the support for academic skills development as an institutionallymanaged "pathway to success" and separated from discipline knowledge. Institutions have embodied what it means to be a successful graduate through generic statements of personal attributes, cognitive abilities and skills (Barrie, Hughes, \& Smith, 2009), more recently including a focus on 21st century skills (e.g. Institute for the Future, 2011) and digital literacies (e.g. Belshaw, 2011). However, there's "little evidence of authentic curriculum integration or of impact on student learning” (Barrie, Hughes, \& Smith, 2009: p. 9).

This kind of coherent, integrated curriculum (Kift, 2009) also requires careful consideration of the diversity of students' prior knowledge and needs, and thus a move towards a more person- alised learning approach. It also requires explicit design choices (Kift, 2009) including forming linkages between subjects, consistency in design elements (e.g. style of marking rubric), articulating expectations, scaffolding and integrating assessment within the curriculum and providing feedback in a timely way that can be used in future work (Kift \& Moody, 2009; Boud, 2009).

\section{Transition as Development}

An alternative viewpoint is to consider transition as development-a transformation that one makes from one "identity" to another (Ecclestone \& Biesta, 2010). Courses viewing transition as development give students a sense not just of the university, but also of their profession, with early field placements, careers activities, stories from recent graduates and practicing professionals all helping students to visualise themselves within the profession. Similarly, a view of transition as development also recognises that students are developing an identity as a higher education student and emerging academic, and so courses taking this approach might concentrate on students taking ownership of their own academic trajectory, and promoting changes in thinking about learning and knowing (Gale \& Parker, 2011).

An important strategy to guide the development of identity is mentoring, widely recognised as beneficial for stronger teacherstudent relationships, reinforcing strengths and challenging new directions, guiding students through difficult times and fostering a sense of community (McInnis et al., 2000, in Jarkey \& Slattery, 2010). Mentoring can "facilitate immense positive change in individuals who have failed to respond to other forms of intervention” (Miles, Power, \& Voerman, 2011: p. 1).

\section{Transition as a Part of "Becoming"}

A third, less common but very powerful approach views transition as a whole-of-life experience that is neither smooth nor necessarily problematic but a means of "becoming" (Gale \& Parker, 2011). Here, transition as an everyday experience, and important responses include openness and flexibility in accommodating for student diversity, a focus on personal planning, and more consideration of "horizontal transitions" between courses and even between institutions to better meet student needs. Graduate attributes are at the heart of new ways of thinking and being, and at the centre of the curriculum as they have the potential to outlast the "knowledge and contexts in which they were originally acquired” (Gale \& Parker, 2011: p. 5).

An inclusive curriculum responsive to increasing diversity accommodates not only for the usual "visible" demographic variables but also diversity in "ways of knowing” (Gale, 2009) and approaches to learning. This moves beyond the usual "labelling” of at risk groups and recognises that students engage with their learning in different ways for different reasons (Krause, 2009). It's these motivations which generate, direct and sustain what they do to learn (Ambrose, Bridges, Lovett, DiPietro, \& Norman, 2010).

Kift (2009) recognised this when she included engagement as a key principle in her "transition pedagogy". Strategies that value prior knowledge, active and collaborative learning, student-generated content, authentic real world tasks and which scaffold for early success, are all important in building an engaging curriculum (Ambrose et al., 2010). Astin (1993) adds 
that the level to which students perceive staff to "care" has a significant influence on retention rates.

The BABM first stage program reported here is an attempt by the course team to embrace a truly integrated strategy to address issues that are multiple and complex, and which ranged from institutional to student specific. The team adopted a multistep, eclectic process that saw a transition in their own thinking of transition from induction to a process of becoming. Firstly, core academic literacies were mapped across first year subjects and integrated into curriculum. Secondly, the team developed a teaching partnership with students via tailored orientation activities and mentoring program. Finally, the first stage subjects were redesigned to maximise linkages and engagement. The overall purpose of this study is to improve the student's first year experience and intrinsically reduce student attrition.

\section{Relevance of This Study to the Higher Education Sector}

It may be argued that initiatives attempting to reduce first year student attrition are most efficient when focussing on large class cohorts. Although this makes economic sense, it does not reflect the nature of commencing full time university students in Australia. Student enrolments at the national level are submitted to the Government using "Fields of Education" (FoE) classification codes, where courses are aggregated at different levels of discipline specificity (2 digit codes are broad and 6 digit codes are specific, but may include several courses). In Australia, the large majority of students will commence their study in a small course, along with less than 20 peers (Figure 1). Students may be aggregated in large fundamental service subjects but will inevitably join small groups when undertaking discipline specific subjects. This study is therefore relevant to a large fraction of the tertiary education sector in Australia.

\section{Methods-Redesigning the First Stage}

The redesign process began with a series of questions, drawn from a wide range of literature, posed to the course team and designed to generate agreed areas of focus. One of the greatest identified areas of need was supporting students' development of academic literacies.

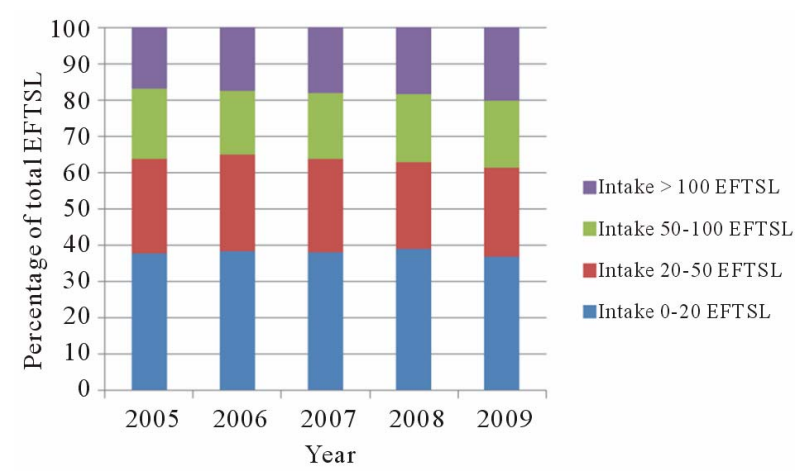

Figure 1.

The distribution of commencing Equivalent Full Time Student Load (EFTSL) in Australia over time. The data presented are for undergraduate, domestic, full time students in all disciplines, in Fields of Education (FoE) codes (six digit level, definition in text). (www.csu.edu.au/ division/plandev/student/national_data/index.htm).

\section{Academic Literacies}

To identify core academic literacies essential for academic and professional life, the team first drew on their own experiences, and aligned these with CSU's graduate attributes, feedback from industry and past and present students, as well as wider research. The agreed literacies included communication skills, analytical skills, problem solving, personal learning, digital literacy and team work. Statements of minimum standards for the first stage were then developed, drawing from the work of the Association of American Colleges and Universities (AACU) (n.d.).

In a vertical mapping exercise, each academic reviewed their subject in relation to whether the six core literacies were taught, practiced or assessed. Individual subject reviews were consolidated into a single "skills map" (Table 1), showing all first stage subjects. In a horizontal mapping exercise, narratives were then consolidated into a summary of how each skill was taught, practiced and assessed across the first stage. This helped to identify gaps and overlaps, and informed subject revisions which integrated skill development within authentic tasks. Later, the narrative was able to be modified for use with students to make the learning and teaching process more explicit.

Recognising that students come to university with varying prior knowledge, the team included an ePortfolio in the course design to help students (and staff) identify individual areas of strength and need in relation to the core literacies, thus helping them develop their own learning trajectory (Hunter et al., 2011). This process was supported through individual mentoring, as well as a multifunctional online resource, Sharpen Your Skills, that acted as a cross-subject toolbox for both staff and students to support formal and informal learning. Subject-based authentic learning activities linked to relevant parts of the toolkit, sometimes as a support resource for formal learning and sometimes as a "reminder" for those still developing skills. Each skill included minimum expectations, self-assessment activities, informal learning resources (e.g. online tutorials) and the subjects/assessments in which students can practice those skills. Demonstration of the skills was included in the assessment rubrics.

The Sharpen Your Skills toolkit drew attention to academic skills as a core aspect of the course, deeply integrated with discipline knowledge and linked to students' development of an academic identity. Combined with the ePortfolio and mentoring strategies, it provided an opportunity for students to take responsibility for their learning and focused on their own areas of need, using "just-in-time” learning activities to support the authentic subject assessments.

\section{Establishing Tertiary Learning Partnerships}

An integrated program of orientation, mentoring, and communication was established to develop a tertiary learning partnership with students. This partnership was designed to facilitate stronger student and staff relationships; increase students' self awareness and sense of identity in relation to their studies; improve their capacity to navigate through university life and understand the expectations that this brings; and to establish a culture of professional mentoring (Ecclestone \& Biesta, 2010).

A course-specific orientation program, with on-campus activities establishing professional and discipline expectations, was developed to supplement the university's generic program as well as assisting students in setting up processes to manage their study-life balance. Students were also introduced to their 
Table 1.

Extract from the mapping document, showing oral communication, subdivided into evidentiary statements, and determining in which subjects components are taught, practiced and assessed. Below the table is a commentary made for one of the components. ( $\mathrm{x}=$ criterion met; ? = unsure).

\begin{tabular}{|c|c|c|c|c|c|c|c|c|c|c|c|c|c|c|c|c|c|c|c|c|c|}
\hline \multirow[b]{2}{*}{ D. Oral communication } & \multicolumn{3}{|c|}{ AGR175 } & \multicolumn{3}{|c|}{ AGB165 } & \multicolumn{3}{|c|}{ AGR156 } & \multicolumn{3}{|c|}{ ECO130 } & \multicolumn{3}{|c|}{ AHT274 } & \multicolumn{3}{|c|}{ MKT110 } & \multicolumn{3}{|c|}{ AGS100 } \\
\hline & $\mathrm{T}$ & $\mathrm{P}$ & A & $\mathrm{T}$ & $\mathrm{P}$ & A & $\mathrm{T}$ & $\mathrm{P}$ & A & $\mathrm{T}$ & $P$ & A & $\mathrm{T}$ & $P$ & A & $\mathrm{T}$ & $P$ & A & $\mathrm{T}$ & $P$ & A \\
\hline $\begin{array}{l}\text { a. Some organization and } \\
\text { structure in presentations }\end{array}$ & $\mathrm{x}$ & $\mathrm{x}$ & $\mathrm{x}$ & & $\mathrm{x}$ & $\mathrm{x}$ & & $\mathrm{x}$ & $\mathrm{x}$ & & & & & & & $\mathrm{x}$ & $\mathrm{x}$ & $\mathrm{x}$ & & ? & ? \\
\hline $\begin{array}{l}\text { b. Central message spelt out, } \\
\text { memorable and not repeated }\end{array}$ & $\mathrm{x}$ & $\mathrm{x}$ & ? & & ? & ? & & $\mathrm{x}$ & $\mathrm{x}$ & & & & & . & & $?$ & ? & ? & & ? & ? \\
\hline $\begin{array}{l}\text { c. Language_-aware of } \\
\text { appropriate language choices } \\
\text { for audience }\end{array}$ & & & & & & & & $\mathrm{x}$ & $\mathrm{x}$ & ? & ? & & & $\stackrel{\mathscr{U}}{\mathbb{U}}$ & & $\mathrm{x}$ & $\mathrm{x}$ & $\mathrm{x}$ & $\mathrm{x}$ & $\mathrm{x}$ & $\mathrm{x}$ \\
\hline $\begin{array}{l}\text { d. Delivery_awareness of } \\
\text { posture, gesture, eye contact, } \\
\text { vocal expressiveness }\end{array}$ & $\mathrm{x}$ & $\mathrm{x}$ & $\mathrm{x}$ & & & & & $\mathrm{x}$ & $\mathrm{x}$ & & & & & 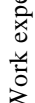 & & $\mathrm{x}$ & $\mathrm{x}$ & $\mathrm{x}$ & & $\mathrm{x}$ & $\mathrm{x}$ \\
\hline $\begin{array}{l}\text { e. Supporting material-use } \\
\text { of supporting material to } \\
\text { establish credibility/authority } \\
\text { on the topic }\end{array}$ & $\mathrm{x}$ & $\mathrm{X}$ & $\mathrm{x}$ & & $\mathrm{x}$ & $?$ & & $\mathrm{x}$ & $\mathrm{x}$ & ? & ? & & & & & $\mathrm{x}$ & $\mathrm{x}$ & $\mathrm{x}$ & & $\mathrm{x}$ & $\mathrm{x}$ \\
\hline
\end{tabular}

Overview: In Semester 1, Weeks 1 - 4, AGR156 students are introduced to oral presentation skills. During Weeks 5 - 8, strategies are reinforced in AGB165 (as part of preparing a presentation on the agricultural industry) and explicitly taught in AGR175 (oral presentation test, giving early feedback on their skills). In Weeks 9 - 12, they practice a group presentation in AGR156, and are assessed on a group presentation in AGR175. In addition, in AGR175 students are encouraged to thank cooperators and this is reinforced in all tours.

learning management system and ePortfolio (PebblePad ${ }^{\circledR}$ ) through some simple exercises, such as identifying assessment schedules, "introducing" themselves and their agricultural background in their ePortfolio, and an introductory survey.

A unique addition to the orientation program was a two-day off-campus tour, visiting numerous agribusiness operators demonstrating the wide range of professional trajectories in which the course might take students. These visits provided points of reference and case studies that were later embedded into several first session subjects. Academics led by example through the facilitation of each visit, and formed a sense of collegiality and community with the students. Community-building exercises also assisted in the establishment of mentoring groups.

While some of the course team members had extensive experience in mentoring, others felt ill-equipped in this role. Thus, after initially identifying the need, the team focused on raising staff awareness and skills through professional development activities with qualified and experienced personnel. These interactions also guided the ultimate shape of the mentoring program, which was designed to build from the foundations established in the orientation program, including the use of the ePortfolio. Although the mentoring program was integrated across the first stage, it was formally embedded in a core first session subject to enable easy timetabling. Mentoring sessions were formally timetabled for one hour per week with fixed groups of 4 - 5 students to 1 - 2 academics, made possible through the course's small student cohort (21 students). Activities involved both small and larger groups, and included both structured (e.g. reflecting on the assessment process and coping with exams) and unstructured sessions (e.g. students seeking advice on assessments). Staff held a debriefing and planning meeting after each session to discuss student progress and respond to needs (Miles, Power, \& Voerman, 2010; Leske, 2008).

An addition to the tertiary learning partnership was the development of an interactive web-based magazine, AgMag (Figure
2), which combined academic information and conversational pieces to link students to the course, School/Faculty research, industry and the greater community. As suggested by Leske (2008), editions of the magazine were strategically timed to meet specific needs (e.g. students' first exam), and included interviews with staff, profiles of past students and industry professionals, video introductions of support staff (e.g. library), news items and social events as well as tips on key academic issues.

\section{Subject and Assessment Redesign}

Subject and assessment redesign aimed to foster constructive

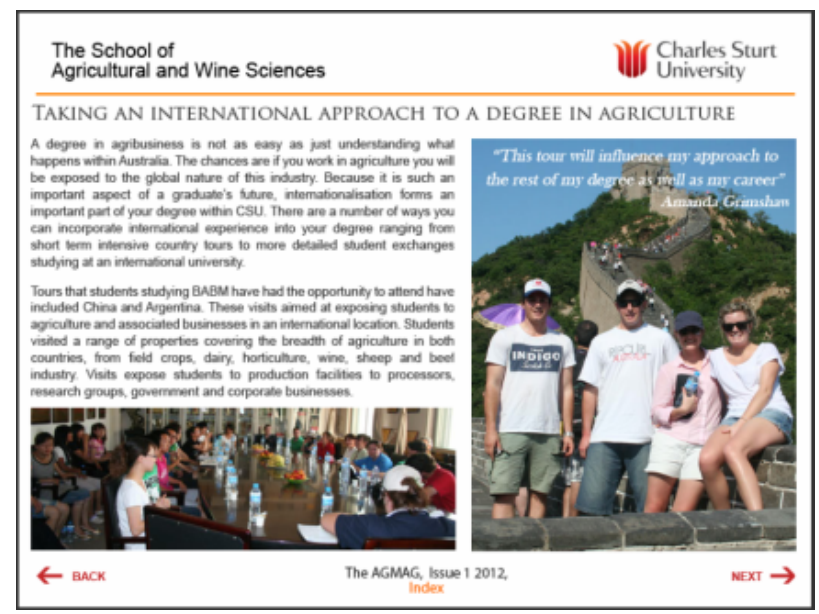

Figure 2.

The AgMag is an interactive PDF file made available to students and industry partners of the Bachelor of Agricultural Business Management. It is published four times a year to reinforce aspects of academic life that are important to students at specific times of the session (orientation, assignments, exams...). 
alignment (Biggs \& Tang, 2007), integrate academic skills in authentic learning tasks, establish linkages between subjects and incorporate strategies that were responsive to diverse needs and promoted student engagement. The process began with an evaluation of the critical areas of threshold knowledge and skills required in each subject, the assessments which might capture this, and the activities/resources required to scaffold its development. This was made explicit to students through concept maps in each subject showing how the various elements connected with each other.

The learning activities aimed to draw students into "patterns of thinking" which are integral to the practice of agribusiness. An important strategy was the use of virtual tutorials and collaborative writing tools, allowing the academic to model and provide immediate feedback to all cohorts, as well as encouraging a deeper connection with the concepts. Real case studies worked towards ensuring the currency and relevance of the subject material, as did student-generated content (e.g. the developing and sharing of project-based assessments in a Wiki).

The skills map formed the basis for embedding relevant academic skills in authentic learning and assessment tasks, supported by the Sharpen Your Skills resources. Assessment for learning was encouraged through opportunities for effective and directed feedback, as well as detailed rubrics which also included academic skills. Key assessments (e.g. a sustainability philosophy and skills developed on work placement) were drawn into the students' ePortfolio, building an emerging sense of the student as a whole.

\section{Results}

When reviewing the effectiveness of the project, the team adopted the first two levels of Kirkpatrick and Kirkpatrick's (2006) four levels of evaluation: 1) Reaction; 2) Learning; 3) Transfer; and 4) Results. In the context of a course, level 4 will only be assessable at the end of the course, when students are close to graduation (and later on, in employment).

\section{Level 1: Reaction}

\section{Orientation Tour Feedback}

The orientation tour was clearly seen as an important component of orientation week as well as a first step towards team building. 26 students participated in the Orientation Tour (OT). Half of the students undertook an online voluntary survey $(\mathrm{n}=$ 13). All responding student agreed or strongly agreed that the orientation program was adequate and that the OT was a valuable addition to the institutional orientation program. As a result, 92\% felt comfortable starting their studies at university. $90 \%$ of responding students liked all aspects of the OT, but particularly the Paintball activity (designed as a social event). Finally, 36\% of responding students thought that the tour would still be valuable even though it could be shorter. These early results were similar to the data collected in 2011 and 2012.

Evidence therefore suggests the tour overcame the lack of engagement early in the degree previously observed by staff and documented by Colclough et al. (2011) and the tour instigated the development of student/lecturer relationships to create a community of learning (McInnis et al., 2000, in Jarkey \& Slattery, 2010).

\section{Student Portfolios-Mentoring Feedback}

Students provided voluntary and ungraded feedback about the mentoring program as an integrated form in their student portfolios in "Introduction to Rural Management" ( $n=13$ out of 21 internal students). Only two students provided feedback in all four feedback opportunities, three on two occasions and the remainder on one occasion.

Overall, the sessions were perceived as good opportunities for communication with academics as well as peers, although one student felt intimidated by the lecturers. Early sessions revealed that students felt comforted by knowing that other students were also anxious about studying at university. The sessions provided early warnings that the students were not comfortable using Pebble Pad. A SWOT self analysis was consistently described as a good experience. Although students did not always identify specific positive outcomes from the mentoring sessions, they consistently valued the opportunity to regroup with lecturers and peers and to be reminded of academic expectations. Students concluded that in order to get the most out of the program, they had to come prepared with a set of clearly formulated questions to the mentors. The quantitative and qualitative nature of the collected data on mentoring feedback was consistent in 2011 and 2012. Student numbers were also consistent in 2011 and 2012.

\section{Level 2: Learning}

CSU collects subject related data for quality control purposes. These data were used to assess the impact of the FYE program on student grades and satisfaction (Table 2). Pass grades and Credit and above grades were used to assess trends in the quality of student grades. A weighted student Grade Point Average (weighting: $\mathrm{HD}=7 ; \mathrm{DI}=6 ; \mathrm{CR}=5$; $\mathrm{PS}=4$ ) was used as a possible predictor of subject performance. Finally, a voluntary standardised online evaluation survey (OES) composed of 9 survey questions (rated out of 7) was used to evaluate student satisfaction (Table 2).

\section{Level 3: Transfer}

Although not consistently measured in this study, academics reported an increase in student attendance as well as participation in class activities. This seemed particularly important in view of a traditional drop in attendance to non compulsory activities after the mid semester break. In the past, it was suggested that after completing 5 - 6 weeks at university, students had become "assignment focussed" and would only participate in activities directly relating to the completion of assignments. Increased class participation was perceived as particularly pleasing because of its positive influence on staff experience. Students did not think that the mentoring program should be extended into the second semester, but actively participated in subject specific mentoring activities. Informal staff feedback indicated that collegiality between students was evident in second semester subjects. Increased collegiality between staff was also reported. Finally, staff reported that students seemed to be more willing to seek assistance from academics than in past years.

\section{Student Attrition}

First year student attrition (i.e. the percentage of student continuing from first year into the second year of the BABM course) was $12 \%$ in 2009 when the BABM team designed the project. In 2010 attrition increased to $19 \%$ and declined to $14 \%$ in 2011. These attrition rates are well below recommended 
Table 2.

Summary of subject data for three of four subjects in the first semester of the Bachelor of Agricultural Business management at Charles Sturt University. GPAs are weighed averages of student distribution marks. OESs are voluntary surveys rated out of 7 . See full description in text.

\begin{tabular}{ccccc}
\hline & Year & \multicolumn{3}{c}{ Subjects } \\
\cline { 3 - 5 } & & AGB165 & AGR156 & AGR175 \\
\hline \multirow{2}{*}{ Pass (\%) } & 2009 & 61 & 59 & 71 \\
& 2010 & 46 & 20 & 70 \\
& 2011 & 40 & 11 & 22 \\
Credit and Above (\%) & 2012 & 57 & 31 & 55 \\
& 2009 & 11 & 35 & 29 \\
Subject Grade Point & 2011 & 25 & 48 & 63 \\
Average (GPA) & 2010 & 4 & 3.3 & 3.7 \\
& 2011 & 3 & 3.7 & 3.9 \\
& 2009 & 3.1 & 4.4 & 4.5 \\
& 2012 & 3.3 & 4.2 & 3.8 \\
Online Evaluation & 2009 & 5 & 5.4 & 4.7 \\
Surveys (OESs) & 2010 & 5.7 & 5.8 & 3.2 \\
& 2012 & 5.8 & 6.1 & 4.5 \\
\hline & & & 6.4 & 4.3 \\
\hline
\end{tabular}

attrition rates within the University. Furthermore, they represent less than half the first year attrition rate of the BABM distance education students in the same course. Due to the small nature of the cohort, a single student leaving the course may represent $4 \%-6 \%$ of the cohort. As a result, the BABM team is satisfied with the current attrition rate but is uncomfortable to call it a "trend".

\section{Discussion and Conclusions}

The FYE project did not consistently increase subject GPAs when compared to the 2009 baseline. It is suggested here that from a computational perspective, the arithmetic nature of the computation of subject GPA makes this indicator insensitive to improved grade distribution when applied to small cohorts. Furthermore, improvement of grades was not of primary concern in this study. At CSU, institutional requirements are that grades be normally distributed and centred on a PS (i.e. the overall subject grade be in the range $50 \%-64.95 \%$ ). This is to (crudely) ensure that subjects are appropriately taught and assessed at tertiary level.

Course objectives extended beyond the crude measurement of student achievement drawn from GPAs. The team reported that students displayed better presentation skills and more reflective tendencies within the first year as well as in subsequent years. Overall, assignments seemed of higher standards, by displaying increased depth, in line with the expectations of the curriculum. These data are in accordance with Astin (1993) and Kift \& Moody (2009), who indicated that the perception of a caring relationship between students and academics resulted in a greater willingness of students to seek assistance than in previous years which has had a positive influence on subject attendance.

Online Evaluation Surveys increased in two of the three subjects reported here and were approximately stable (except in 2010) in AGR175 and first year attrition rates are decreased in 2011 following an increase in 2010. This is particularly critical in view of a global shortage of agricultural tertiary graduates.

The BABM course is therefore facing the unusual reality that although students are not achieving better grades than their 2009 peers, they are overall happier in the subjects. This seems to contradict the belief that students are mostly "assessment focussed" and seems to indicate that students' appreciation of their studies include (in addition to grades) a sense of "worth" of the subjects studied. This is critical, in view of the perception that students are an important agent for course (and institutional) marketing.

Following the above analysis, the BABM team concluded of the overall success of the project. It was however acknowledged that a FYE at university is a combination of a large amount of variables, many of them out of the control of academics. This complex experience is therefore difficult to assess and quantify particularly in view of a number of interrelated issues. This program has only been implemented for a few years and a needs adjusting in coming years, such as the capture of the most appropriate quantitative and qualitative data.

Beyond the impact on students, significant impacts have also been experienced in academic commitment to curriculum renewal. The collaborative approach and shared awareness of and responsibility for student development through the mentoring program resulted in cohesive teaching strategies with consistent messages now reaching all students regarding the expectations of academic life. It helped them identify students who needed additional support, and fostered team spirit between students and academics, in line with the observations of McInnis et al. (2000) and Jarkey \& Slattery (2010). Following the mapping process, academics became more aware of what was happening in other subjects, and were better able to make linkages between subjects with students. From an institutional point of view, the various initiatives resulted in opportunities to showcase an integrated course approach, which was very well-received in other areas of the university. The time investment by the various members of the BABM team was however very high due to the large amount of original work, hence return on investment (Kaufman, 1996) may be considered as low when based on quantitative data only and excluding the gratifying feeling of the betterment of the course.

The course team now continues to meet on a fortnightly basis to work on new and existing initiatives, and there has been a change towards more collaborative course decision-making as the team becomes more actively engaged in improving the overall student experience. While elements of all three "approaches” to transition, as proposed by Gale \& Parker (2011) are apparent in the various initiatives employed, there was a definite change in thinking from a transition as induction to transition as becoming, and this is informing future iterations of the program. This is an evolving cultural change in the approach of the educators and the institution within the first year, which will continue to develop based on the successful elements of previous programs (Gale \& Parker, 2011). The academics' enthusiasm for and belief in the initiatives has mani- 
fested in a preparedness to work over and above their formal workload allocations. This illustrates a positive cultural change from individual subject development to a more holistic consideration of the student experience.

However, for such changes to be sustainable, ongoing financial and workload support need to be an integral part of the curriculum renewal process. While there is substantial financial commitment across the university to improve the first year experience (realised at CSU through the Student Transition and Retention (STAR) program), funding for individual course initiatives has been limited. For example, the two-day orientation tour needed to be partly funded through student contributions. There is a clear need for management to recognise the time and funding needed for significant curriculum change.

Academic and student feedback identified several areas for further improvement. More effective communication is needed prior to orientation to ensure students are fully prepared for the overnight tour and mentoring program, in particular the provision of information packages to parents about the program and on-line support for the university's student platform. In addition, initial frustrations associated with the publication of the AgMag highlighted the importance of coordinating timelines and workflows with other divisions to overcome competing priorities. The academics also identified the importance of a consistent format in the mentoring program to keep students focused and enthusiastic.

In conclusion, the success of the BABM first year initiative lay in the combination of all its parts rather than one single entity. It is now time for this project to move into its next phase. Monitoring the progression of students in later years following their involvement within the project will create a greater understanding of the merits of such programs on the long term development of the undergraduate.

\section{Acknowledgments}

The authors acknowledge other members of the BABM team (especially Kerry Cochrane, Richard Culas and Dennis Hodgkins) who contributed to these initiatives. We would also like to recognise the critical roles of Paul Worsfold (Career Development Service), David Ross (Learning Skills Adviser) and Division of Learning and Teaching Services production staff in this initiative.

\section{REFERENCES}

Ambrose, S., Bridges, M., Lovett, M., DiPietro, M., \& Norman, M. (2010). How learning works: 7 research-based principles for smart teaching. San Francisco, CA: Jossey-Bass.

Association of American Colleges and Universities (n.d.). VALUE: Valid assessment of learning in undergraduate education.

http://www.aacu.org/value/index.cfm

Astin, A. W. (1993). What matters in college? Four critical years revisited. San Francisco, CA: Jossey-Bass.

Barrie, S., Hughes, C., \& Smith, C. (2009). National Graduate Attributes Project: Integration and assessment of graduate attributes in curriculum. Strawberry Hills, NSW: Australian Learning and Teaching Council. http://www.itl.usyd.edu.au/projects/nationalgap

Belshaw, D. (2011). The never ending thesis.

http://neverendingthesis.com/

Biggs, J., \& Tang, C. (2007). Teaching for quality learning at univer- sity: What the student does (3rd ed.). Berkshire: McGraw-Hill.

Boud, D., \& Associates (2010). Assessment 2020: Seven propositions for assessment reform in higher education. Sydney: Australian Learning and Teaching Council. www.assessmentfutures.com

Charles Sturt University (n.d.). Curriculum renewal. http://www.csu.edu.au/division/landt/curriculumrenewal/index.htm

Colclough, G., Kimmins, L., Harmes, M., \& Henderson, L. (2011). Re-living first year-The first weeks. In 14th Pacific rim First Year in Higher Education (FYHE) conference 2011.

http://www.fyhe.com.au/past_papers/papers11/FYHE-2011/content/p df/2F.pdf

Ecclestone, K., \& Biesta, G. (2010). Transitions and learning through the lifecourse. London: Routledge.

Gale, T. (2009). Towards a southern theory of higher education. Keynote address. In Proceedings of 12th Pacific rim First Year in Higher Education conference (pp. 1-15). Brisbane, QLD: Queensland University of Technology.

http://www.fyhe.com.au/past_papers/papers09/ppts/Trevor_Gale_pa per.pdf

Gale, T., \& Parker, S. (2011). Good practice report: Student transition into higher education. Strawberry Hills, NSW: Australian Learning \& Teaching Council.

Hunter, C., Guisard, Y., Behrendt, K., Bone, Z., Cochrane, K., \& Wheatley, W. (2011). Developing professional identity. In S. Sutherland, J. Brotchie, \& S. Chesney (Eds.), Pebblegogy-Ideas and activities to inspire and engage learners (pp. 118-123). Telford: Pebble Learning Ltd.

Institute for the Future (2011). Future work skills 2020. San Francisco, CA: University of Phoenix Research Institute. http://www.iftf.org/futureworkskills2020

Kift, S. (2009). Articulating a transition pedagogy to scaffold and to enhance the first year student learning experience in Australian higher education: Final report for ALTC Senior Fellowship Program. Strawberry Hills, NSW: Australian Learning and Teaching Council.

Kift, S. M., \& Moody, K. E. (2009). Harnessing assessment and feedback in the first year to support learning success, engagement and retention. In Proceedings of ATN assessment conference. Melbourne, VIC: RMIT University. http://eprints.qut.edu.au/28849/

Kift, S., Nelson, K., \& Clarke, J. (2010). Transition pedagogy: A third generation approach to FYE-A case study of policy and practice for the higher education sector. The International Journal of the First Year in Higher Education, 1, 1-20.

Kirkpatrick, D. L., \& Kirkpatrick, J. D. (2006). Evaluating training programs (3rd ed.). San Francisco, CA: Berrett-Koehler Publishers.

Krause, L. (2008). Commentary on first-year curriculum case studies: Demographics and patterns of engagement perspective. Strawberry Hills, NSW: Australian Learning and Teaching Council.

Leske, J. (2008). Commentary on first year curriculum case studies: Orientation and transition perspective. Strawberry Hills, NSW: Australian Learning and Teaching Council.

McInnis, C., James, R., \& Hartley, R. (2000). Trends in the first year experience in Australian universities. In N. Jarkey, \& K. Slattery (Eds.), When good mentoring programs seem bad: Managing expectations for ever-increasing numbers of first years. Melbourne, VIC: DETYA/University of Melbourne, Centre for the Study of Higher Education.

http://www.fyhe.com.au/past_papers/papers10/content/pdf/11E.pdf

Miles, B., Power, R., \& Voerman, A. (2010). Building bridges: A practical guide to developing and implementing a subject-specific peerto-peer academic mentoring program for first-year higher education students. In 14th Pacific rim First Year in Higher Education (FYHE) conference 2011.

http://www.fyhe.com.au/past_papers/papers11/FYHE-2011/content/p df/1B.pdf

Upcraft, M. L., Gardner, J. N., \& Barefoot, B. O. (Eds.). (2005). Challenging and supporting the first-year student: A handbook for improving the first year of college. San Francisco, CA: Jossey-Bass. 